\title{
Ongoing Microbiology Susceptibility
}

National Cancer Institute

\section{Source}

National Cancer Institute. Ongoing Microbiology Susceptibility. NCI Thesaurus. Code C162328.

An indication or description that a microbiology susceptibility assessment is continuing. 